\title{
Prediction of indirect interactions in proteins
}

\author{
Peteris Prusis ${ }^{1,2}$, Staffan Uhlén ${ }^{1,3}$, Ramona Petrovska1, Maris Lapinsh ${ }^{1}$ and \\ Jarl ES Wikberg*1
}

\author{
Address: ${ }^{1}$ Department of Pharmaceutical Biosciences, Uppsala University, Uppsala, Sweden, ${ }^{2}$ Linnaeus Center for Bioinformatics, Uppsala \\ University, Uppsala, Sweden and 3Section for Pharmacology, The University of Bergen, Bergen, Norway \\ Email: Peteris Prusis - peteris.prusis@farmbio.uu.se; Staffan Uhlén - staffan.uhlen@med.uib.no; \\ Ramona Petrovska - ramona.petrovska@farmbio.uu.se; Maris Lapinsh - maris.lapinsh@farmbio.uu.se; \\ Jarl ES Wikberg* - jarl.wikberg@farmbio.uu.se \\ * Corresponding author
}

Published: 22 March 2006

BMC Bioinformatics2006, 7:167 doi:10.1 186/147|-2105-7-167
Received: 09 December 2005

Accepted: 22 March 2006

This article is available from: http://www.biomedcentral.com//47/-2/05/7//67

(c) 2006Prusis et al; licensee BioMed Central Ltd.

This is an Open Access article distributed under the terms of the Creative Commons Attribution License (http://creativecommons.org/licenses/by/2.0), which permits unrestricted use, distribution, and reproduction in any medium, provided the original work is properly cited.

\begin{abstract}
Background: Both direct and indirect interactions determine molecular recognition of ligands by proteins. Indirect interactions can be defined as effects on recognition controlled from distant sites in the proteins, e.g. by changes in protein conformation and mobility, whereas direct interactions occur in close proximity of the protein's amino acids and the ligand. Molecular recognition is traditionally studied using three-dimensional methods, but with such techniques it is difficult to predict the effects caused by mutational changes of amino acids located far away from the ligandbinding site. We recently developed an approach, proteochemometrics, to the study of molecular recognition that models the chemical effects involved in the recognition of ligands by proteins using statistical sampling and mathematical modelling.

Results: A proteochemometric model was built, based on a statistically designed protein library's (melanocortin receptors') interaction with three peptides and used to predict which amino acids and sequence fragments that are involved in direct and indirect ligand interactions. The model predictions were confirmed by directed mutagenesis. The predicted presumed direct interactions were in good agreement with previous three-dimensional studies of ligand recognition. However, in addition the model could also correctly predict the location of indirect effects on ligand recognition arising from distant sites in the receptors, something that three-dimensional modelling could not afford.

Conclusion: We demonstrate experimentally that proteochemometric modelling can be used with high accuracy to predict the site of origin of direct and indirect effects on ligand recognitions by proteins.
\end{abstract}

\section{Background}

The processes of life depend on intermolecular recognition. Molecular recognition by proteins is a complex process that is determined not only by direct interactions of a protein with the interacting molecule, but also by indirect effects arising at distant sites in the proteins. Using threedimensional (3D) structure approaches it is not straightforward to analyze long distance effects on, for example, protein conformation, mobility, and stability. Recently, a new approach using statistical analysis of protein and lig- 
Table I: Affinities of multiple chimeric melanocortin receptors. Affinities (pK \pm standard deviation, SD) of multiple chimeric melanocortin receptors for $\alpha-M S H$, NDP-MSH and [125I]-NDP-MSH determined by radioligand binding.

\begin{tabular}{|c|c|c|c|c|c|c|c|c|}
\hline \multirow[t]{2}{*}{ № } & \multirow[t]{2}{*}{ Name } & \multirow[t]{2}{*}{ Set } & \multicolumn{3}{|c|}{ Parts } & \multicolumn{3}{|c|}{$\mathrm{pK}$} \\
\hline & & & A & B & C & $\begin{array}{c}\text { 125|-NDP- } \\
\text { MSH }\end{array}$ & NDP-MSH & $\alpha-\mathrm{MSH}$ \\
\hline 1 & $M C_{1}$ & wt. & $M C_{1}$ & $M C_{1}$ & $M C_{1}$ & $9.96^{\mathrm{a}}$ & $10.34^{a}$ & $9.68^{a}$ \\
\hline 2 & $M C_{3}$ & wt. & $M C_{3}$ & $\mathrm{MC}_{3}$ & $M C_{3}$ & $9.40^{\mathrm{a}}$ & $9.31 \mathrm{a}$ & $7.27^{\mathrm{a}}$ \\
\hline 3 & $\mathrm{MC}_{4}$ & wt. & $\mathrm{MC}_{4}$ & $\mathrm{MC}_{4}$ & $\mathrm{MC}_{4}$ & $8.64^{a}$ & $8.73^{a}$ & $5.69 a$ \\
\hline 4 & $M C_{5}$ & wt. & $\mathrm{MC}_{5}$ & $M C_{5}$ & $\mathrm{MC}_{5}$ & $8.54^{\mathrm{a}}$ & $8.58^{a}$ & $5.30^{\mathrm{a}}$ \\
\hline 5 & $\mathrm{FI} 34$ & $\mathrm{~F}$ & $M C_{1}$ & $\mathrm{MC}_{3}$ & $M C_{4}$ & $8.58 \pm 0.17$ & $10.37 \pm 0.01$ & $7.70 \pm 0.14$ \\
\hline 6 & $\mathrm{FI} 53$ & $\mathrm{~F}$ & $M C_{1}$ & $\mathrm{MC}_{5}$ & $M C_{3}$ & $8.88 \pm 0.16$ & $10.38 \pm 0.12$ & $7.80 \pm 0.56$ \\
\hline 7 & F354 & $\mathrm{F}$ & $\mathrm{MC}_{3}$ & $\mathrm{MC}_{5}$ & $\mathrm{MC}_{4}$ & $8.80 \pm 0.16$ & $8.66 \pm 0.48$ & $5.72 \pm 0.65$ \\
\hline 8 & $\mathrm{~F} 413$ & $\mathrm{~F}$ & $\mathrm{MC}_{4}$ & $M C_{1}$ & $\mathrm{MC}_{3}$ & $8.62 \pm 0.16$ & $8.64 \pm 0.16$ & $6.21 \pm 0.42$ \\
\hline 9 & F435 & $\mathrm{F}$ & $\mathrm{MC}_{4}$ & $M C_{3}$ & $M C_{5}$ & $8.96 \pm 0.08$ & $8.81 \pm 0.14$ & $6.39 \pm 0.40$ \\
\hline 10 & F45I & $\mathrm{F}$ & $\mathrm{MC}_{4}$ & $\mathrm{MC}_{5}$ & $M C_{1}$ & $9.06 \pm 0.31$ & $8.54 \pm 0.26$ & $6.33 \pm 0.43$ \\
\hline 11 & $\mathrm{~F} 5 \mathrm{I} 4$ & $\mathrm{~F}$ & $\mathrm{MC}_{5}$ & $M C_{1}$ & $\mathrm{MC}_{4}$ & $9.19 \pm 0.21$ & $8.45 \pm 0.11$ & $5.11 \pm 0.14$ \\
\hline 12 & F53I & $\mathrm{F}$ & $\mathrm{MC}_{5}$ & $\mathrm{MC}_{3}$ & $M C_{1}$ & $8.67 \pm 0.48$ & $10.85 \pm 0.28$ & $5.33 \pm 0.08$ \\
\hline 13 & F543 & $\mathrm{F}$ & $M C_{5}$ & $\mathrm{MC}_{4}$ & $M C_{3}$ & $9.24 \pm 0.25$ & $9.51 \pm 0.50$ & $6.39 \pm 0.50$ \\
\hline 14 & $\mathrm{SI} 34$ & $S$ & $M C_{1}$ & $\mathrm{MC}_{3}$ & $\mathrm{MC}_{4}$ & $9.30 \pm 0.26$ & $9.98 \pm 0.16$ & $9.02 \pm 0.22$ \\
\hline 15 & S354 & $S$ & $\mathrm{MC}_{3}$ & $\mathrm{MC}_{5}$ & $\mathrm{MC}_{4}$ & $8.81 \pm 0.18$ & $8.62 \pm 0.37$ & $4.88 \pm 0.25$ \\
\hline 16 & S45I & $S$ & $\mathrm{MC}_{4}$ & $M C_{5}$ & $M C_{1}$ & $9.06 \pm 0.31$ & $9.35 \pm 0.36$ & $6.10 \pm 0.16$ \\
\hline 17 & S5I4 & $S$ & $\mathrm{MC}_{5}$ & $M C_{1}$ & $\mathrm{MC}_{4}$ & $9.19 \pm 0.21$ & $10.04 \pm 0.31$ & $7.31 \pm 0.38$ \\
\hline 18 & S53I & $S$ & $M C_{5}$ & $\mathrm{MC}_{3}$ & $M C_{1}$ & $8.96 \pm 0.35$ & $9.18 \pm 0.65$ & $7.57 \pm 0.19$ \\
\hline
\end{tabular}

aData for $M C_{1}, M C_{3}, M C_{4}$, and $M C_{5}$ taken from [3I].

and interaction space, proteochemometrics, was developed [1,2]. It was used to model protein-peptide interactions and interactions of proteins with organic compounds [1,3-7]. Here we show its utility in predicting indirect effects in proteins.

Proteochemometrics originates from chemometrics, the mathematical methods used to analyze chemical data. Proteochemometrics aims to describe the interactions between a series of macromolecules (such as proteins) and a series of ligands. Proteochemometric models are thereby created. These models are useful for predicting the affinities of new proteins for their ligands if the new molecules fall within the description space of the protein-ligand pairs of the training data set. A proteochemometric experiment is typically described by three descriptor blocks; the ligand descriptor $\left(D^{L}\right)$, protein descriptor $\left(D^{P}\right)$, and ligand-protein cross-term $\left(D^{L P}\right)$ blocks. A vector of numbers, called the ligand descriptors $\left(D^{L}\right)$, characterizes each ligand $L$. Similarly, each protein $P$ has its protein descriptors $\left(D^{P}\right)$. If we use a linear method of regression, the negative logarithm of ligand $L$ 's affinity $\left(p K_{L P}\right)$ for the protein $P$ is expressed by:

$p K_{L P}=\overline{p K}+\sum_{i}^{N} C_{i} D_{i}^{L}+\sum_{j}^{M} C_{j} D_{j}^{P}+\sum_{i}^{N} \sum_{j}^{M} C_{i j} D_{i j}^{L P}$

where $\overline{p K}$ is the average affinity, $C_{i}, C_{j}$, and $C_{i j}$ are the regression coefficients for ligand descriptors, protein descriptors, and ligand-protein cross-terms, respectively, and $N$ and $M$ are the number of descriptors for ligands and proteins, respectively.

Ligand-protein cross-terms are usually defined by a new vector that is formed by multiplying each ligand descriptor with each receptor descriptor of particular ligandreceptor pairs. Hence,

$D_{i j}^{L P}=D_{i}^{L} D_{j}^{P} \quad$ Eq. 2

and then

$p K_{L P}=\overline{p K}+\sum_{i}^{N} C_{i} D_{i}^{L}+\sum_{j}^{M} C_{j} D_{j}^{P}+\sum_{i}^{N} D_{i}^{L}\left[\sum_{j}^{M} C_{i j} D_{j}^{P}\right]$

By using Eq. 3, the selectivity, $S_{L A B}$, between protein $A$ and protein $B$ for some particular ligand $L$ can be expressed as:

$S_{L A B}=p K_{L A}-p K_{L B}=\sum_{j}^{M} C_{j}\left(D_{j}^{A}-D_{j}^{B}\right)+\sum_{i}^{N} D_{i}^{L}\left[\sum_{j}^{M} C_{i j}\left(D_{j}^{A}-D_{j}^{B}\right)\right] \quad E q .4$

If a region $U$ of a protein is described by the set of descriptors, $V$, then the contribution to the selectivity, $S_{L A B}^{U}$, by $U$ between proteins $A$ and $B$ for ligand $L$ is obtained by:

$S_{L A B}^{U}=\sum_{j \in V}^{K} C_{j}\left(D_{j}^{A}-D_{j}^{B}\right)+\sum_{i}^{N} D_{i}^{L}\left[\sum_{j \in V}^{K} C_{i j}\left(D_{j}^{A}-D_{j}^{B}\right)\right]$ 
Table 2: Performance of proteochemometric models. Performance of proteochemometric models derived using wild-type and

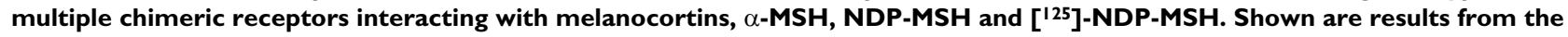
model based on binary receptor descriptors $(A)$ and the model based on physicochemical description of amino acids of the transmembrane regions presumed to face in a direction opposite to the membrane (B) (see Methods for further details).

\begin{tabular}{ccccccc}
\hline Model & $\mathrm{R}^{2}$ & $\mathrm{RMSE}(\log (\mathrm{M}))$ & $\mathrm{Q}^{2}$ & $\mathrm{iR}^{2}$ & $\mathrm{iQ}^{2}$ & $\mathrm{eQ}$ \\
\hline $\mathrm{A}$ & 0.91 & 0.45 & 0.83 & 0.49 & -0.21 & 0.84 \\
$\mathrm{~B}$ & 0.91 & 0.46 & 0.82 & 0.46 & -0.25 & 0.85 \\
\hline
\end{tabular}

Accordingly, we can localize regions in a protein that afford selectivity (i.e., functionality difference between protein pairs) for a particular ligand by applying Eq. 5. A region can be a subsequence, a 3D molecular interaction field, a single amino acid, or even a physicochemical property of an individual amino acid, and is only restricted by the way the descriptors are assigned to the proteins [1-7]. Since Eq. 5 places no restriction how far in space a ligand is located from a region in a protein, proteochemometrics is useful to predict indirect interactions in proteins.

\section{Results}

Design and testing of multiple chimeric melanocortin receptor library

It is necessary to have modifications of both the proteins and ligands, preferably both in the form of a series (i.e., "libraries"), in order to use Eq. 5. Here we used a library of multiple chimeric melanocortin receptors [7]. Briefly, the library was created from four natural melanocortin receptors $\left(\mathrm{MC}_{1}, \mathrm{MC}_{3-5}\right)$. Each receptor was divided into five sequence fragments (S1-S5) and multiple chimeric receptors were then obtained by systematically shuffling the fragments. In order to maximize the chemical space information of the receptors, while keeping the number of experiments as low as possible, statistical molecular design was applied to properly select the sequence fragments [7-10]. The entire receptor library comprised 18 receptors and was tested for its interaction with the native melanocortin ligand, $\alpha-\mathrm{MSH}$ and the synthetic MSH analogues NDP-MSH and [125I]-NDP-MSH (see Table 1).

\section{Proteochemometrics modelling}

Interpretation of $E q .5$ is dependent on our description of the proteins. Here two proteochemometrics models were created. One was based on a binary description of the proteins. The other used physicochemical descriptions of amino acids located inside transmembrane regions with presumed proximity to possible ligand binding cleft(s) according to the $\mathrm{x}$-ray structure of bovine rhodopsin $[7,11,12]$. The binary model comprised information on the extent to which segments S1-S5 are involved in the selective recognition of ligands by the receptors, while the model based on physicochemical descriptions of amino acids comprised information on the contributions of single amino acids. Both models performed excellently in state-of-the-art model validations (see Table 2).

\section{Prediction of ligand recognition}

The models were used to compute selectivity recognition maps for all melanocortin receptor pairs for the $\alpha-\mathrm{MSH}$ hormone (see Tables 3 and 4). $\alpha$-MSH is recognized by $\mathrm{MC}$ receptors, albeit it binds with more than 1000 times higher affinity to the $\mathrm{MC}_{1}$ receptor than to the $\mathrm{MC}_{4}$ receptor. The recognition map derived from the binary model predicted that segments $\mathrm{S} 1, \mathrm{~S} 2$, and S4 play major roles for the $\alpha$-MSH $\mathrm{MC}_{1} / \mathrm{MC}_{4}$ selectivity, while S3 and S5 contribute only a little (Fig. 1). The involvement of S1 and S2 was expected, as these regions possess amino acids close to the ligand recognition site according to 3D modelling [11]. However, the whole S4 region was located farther away, and its involvement was therefore more surprising. The model based on amino-acid physicochemical properties

Table 3: Selectivity recognition map predicted from binary model. Selectivity recognition map for wild-type MC receptor pairs for $\alpha$ MSH computed from the binary proteochemometric model. The contribution to the selectivity $S^{u}$, log(M), for indicated segments SIS5, was computed from the model using Eq. 5. Total selectivity represents the entire differences in affinity between receptor pairs computed from the model (see Eq. 4).

\begin{tabular}{|c|c|c|c|c|c|c|}
\hline \multirow[t]{2}{*}{ Segment } & \multicolumn{6}{|c|}{ Contribution to selectivity $S^{u},(\log (M))$} \\
\hline & $M C_{1} / M_{3}$ & $M C_{1} / M_{4}$ & $M C_{1} / M_{5}$ & $\mathrm{MC}_{3} / \mathrm{MC}_{4}$ & $M C_{3} / \mathrm{MC}_{5}$ & $\mathrm{MC}_{4} / \mathrm{MC}_{5}$ \\
\hline SI & 1.14 & 1.07 & 1.04 & -0.07 & -0.09 & -0.02 \\
\hline S2 & 0.39 & 0.91 & 1.15 & 0.52 & 0.77 & 0.24 \\
\hline S3 & -0.15 & 0.33 & 0.44 & 0.49 & 0.60 & 0.11 \\
\hline S4 & -0.07 & 0.54 & 0.62 & 0.61 & 0.69 & 0.08 \\
\hline S5 & 0.10 & 0.29 & 0.46 & 0.19 & 0.36 & 0.17 \\
\hline Total selectivity & 1.40253 & 3.1389 & 3.71986 & 1.73638 & 2.31735 & 0.58095 \\
\hline
\end{tabular}


Table 4: Predicted amino acid selectivity recognition map. Amino acid selectivity recognition map for MC receptors for $\alpha-M S H$ computed from the proteochemometric model based on the physicochemical description of amino acids of the transmembrane regions presumed to facing in the direction opposite to the membrane. The contributions to selectivity $S^{u}, \log (M)$, of the indicated amino acid positions were computed from the model using Eq. 5 . Total selectivity represents the entire difference in affinity between receptor pairs computed from the model (see Eq. 4). TM, transmembrane regions; SG, segments.

\begin{tabular}{|c|c|c|c|c|c|c|c|c|c|c|c|}
\hline \multicolumn{4}{|c|}{ Amino Acids } & \multirow[t]{2}{*}{ TM } & \multirow[t]{2}{*}{ SG } & \multicolumn{6}{|c|}{ Contribution to selectivity $S^{u},(\log (M))$} \\
\hline$M C_{1}$ & $\mathrm{MC}_{3}$ & $\mathrm{MC}_{4}$ & $\mathrm{MC}_{5}$ & & & $M C_{1} / M C_{3}$ & $M C_{1} / M_{4}$ & $M C_{1} / M_{5}$ & $\mathrm{MC}_{3} / \mathrm{MC}_{4}$ & $M C_{3} / \mathrm{MC}_{5}$ & $\mathrm{MC}_{4} / \mathrm{MC}_{5}$ \\
\hline Glu37 & $\mathrm{G} \ln 74$ & $\mathrm{Gln} 43$ & Asp35 & I & $\mathrm{SI}$ & 0.23 & 0.23 & 0.18 & 0.00 & -0.05 & -0.05 \\
\hline Val38 & Val75 & Leu44 & Met36 & I & SI & 0.00 & 0.11 & 0.12 & 0.11 & 0.12 & 0.00 \\
\hline Ser4I & Lys78 & Ser47 & Ala39 & I & SI & 0.04 & 0.00 & 0.05 & -0.04 & 0.01 & 0.05 \\
\hline Asp42 & Pro79 & Pro48 & Val40 & I & SI & 0.21 & 0.21 & 0.21 & 0.00 & 0.00 & 0.00 \\
\hline Val60 & Ile97 & Ile66 & Ile58 & 1 & SI & 0.48 & 0.48 & 0.48 & 0.00 & 0.00 & 0.00 \\
\hline Ile63 & Vallo0 & Ile69 & Ile6I & I & SI & 0.07 & 0.00 & 0.00 & -0.07 & -0.07 & 0.00 \\
\hline Ile77 & Leul|4 & Ile83 & Val75 & 2 & S2 & -0.11 & 0.00 & 0.07 & 0.11 & 0.18 & 0.07 \\
\hline Ser83 & Ala | 20 & Ala89 & Ala8I & 2 & S2 & 0.14 & 0.14 & 0.14 & 0.00 & 0.00 & 0.00 \\
\hline Asn9l & Asn 128 & Asn97 & Ser89 & 2 & $\mathrm{~S} 2$ & 0.00 & 0.00 & 0.14 & 0.00 & 0.14 & 0.14 \\
\hline Val92 & Ala $\mid 29$ & Gly98 & Ala90 & 2 & S2 & 0.03 & 0.10 & 0.03 & 0.07 & 0.00 & -0.07 \\
\hline Ala96 & Ilel33 & Ilel02 & Ile94 & 2 & S2 & 0.14 & 0.14 & 0.14 & 0.00 & 0.00 & 0.00 \\
\hline Leu99 & Ala | 36 & Thrl05 & Tyr97 & 2 & S2 & -0.01 & 0.05 & 0.06 & 0.06 & 0.07 & 0.01 \\
\hline Gln II4 & $G \ln |5|$ & Vall I9 & Argl I 2 & 3 & S2 & 0.00 & 0.08 & 0.11 & 0.08 & 0.11 & 0.03 \\
\hline LeulI6 & MetI53 & |lel2I & Ilel|4 & 3 & $\mathrm{~S} 2$ & -0.16 & 0.01 & 0.01 & 0.17 & 0.17 & 0.00 \\
\hline Ilel 20 & Phel 57 & Ilel 25 & Phel I8 & 3 & S2 & -0.03 & 0.00 & -0.03 & 0.03 & 0.00 & -0.03 \\
\hline Thr I24 & Ilel6I & Ilel29 & Ilel 22 & 3 & S2 & 0.14 & 0.14 & 0.14 & 0.00 & 0.00 & 0.00 \\
\hline Met 128 & Leul65 & Leul33 & Vall26 & 3 & S2 & 0.09 & 0.09 & 0.11 & 0.00 & 0.02 & 0.02 \\
\hline Leul29 & Vall 66 & Leu I34 & Vall27 & 3 & S2 & -0.03 & 0.00 & -0.03 & 0.03 & 0.00 & -0.03 \\
\hline Leul32 & Ilel69 & Ilel37 & Met I 30 & 3 & S2 & 0.01 & 0.01 & 0.15 & 0.00 & 0.14 & 0.14 \\
\hline Gly 136 & Leul73 & Leul4I & Leu I34 & 3 & S2 & 0.14 & 0.14 & 0.14 & 0.00 & 0.00 & 0.00 \\
\hline Alal7I & Cys208 & Ala I76 & Phel69 & 4 & S3 & -0.09 & 0.00 & 0.04 & 0.09 & 0.13 & 0.04 \\
\hline Serl72 & Cys209 & CysI77 & CysI70 & 4 & S3 & 0.12 & 0.12 & 0.12 & 0.00 & 0.00 & 0.00 \\
\hline Phel75 & Cys 212 & Ser 180 & Cys I73 & 4 & S3 & 0.02 & 0.11 & 0.02 & 0.09 & 0.00 & -0.09 \\
\hline Ser 176 & Gly213 & Gly|8I & Gly I74 & 4 & S3 & 0.12 & 0.12 & 0.12 & 0.00 & 0.00 & 0.00 \\
\hline Aspl84 & Glu22I & Asp 189 & Glul 82 & 5 & S3 & -0.07 & 0.00 & -0.07 & 0.07 & 0.00 & -0.07 \\
\hline Alal 87 & Met224 & Alal 92 & Tyr 185 & 5 & S3 & -0.08 & 0.00 & -0.03 & 0.08 & 0.05 & -0.03 \\
\hline Phel95 & Met232 & Met200 & MetI93 & 5 & S3 & 0.12 & 0.12 & 0.12 & 0.00 & 0.00 & 0.00 \\
\hline Leu200 & Met237 & Leu205 & Leul98 & 5 & S3 & -0.26 & 0.00 & 0.00 & 0.26 & 0.26 & 0.00 \\
\hline Met203 & Met240 & Met208 & Leu20I & 5 & S3 & 0.00 & 0.00 & 0.16 & 0.00 & 0.16 & 0.16 \\
\hline Leu243 & Ile28I & Leu247 & Val240 & 6 & S4 & -0.07 & 0.00 & 0.63 & 0.07 & 0.70 & 0.63 \\
\hline Leu247 & Leu285 & Ile25I & Leu244 & 6 & S4 & 0.00 & 0.57 & 0.00 & 0.57 & 0.00 & -0.57 \\
\hline Ile264 & Ile302 & Tyr268 & Met26I & 6 & S5 & 0.00 & 0.13 & 0.12 & 0.13 & 0.12 & 0.00 \\
\hline Val265 & Ile303 & Ile269 & Leu262 & 6 & S5 & 0.02 & 0.02 & 0.11 & 0.00 & 0.09 & 0.09 \\
\hline Ala285 & Val323 & Ile289 & Ile282 & 7 & S5 & 0.02 & 0.06 & 0.06 & 0.05 & 0.05 & 0.00 \\
\hline Ile288 & Met326 & Met292 & Met285 & 7 & S5 & 0.04 & 0.04 & 0.04 & 0.00 & 0.00 & 0.00 \\
\hline Ala29I & Ser329 & Ser295 & Ser288 & 7 & S5 & 0.04 & 0.04 & 0.04 & 0.00 & 0.00 & 0.00 \\
\hline \multirow[t]{2}{*}{ Ile292 } & Val330 & Ile296 & Val289 & 7 & S5 & -0.01 & 0.00 & -0.01 & 0.01 & 0.00 & -0.01 \\
\hline & \multicolumn{2}{|c|}{ Total selectivity } & & - & & 1.30 & 3.26 & 3.70 & 1.96 & 2.40 & 0.44 \\
\hline
\end{tabular}

in the transmembrane regions indicated that three amino acids in $\mathrm{S} 1$, five in $\mathrm{S} 2$, one in $\mathrm{S} 4$, and one in $\mathrm{S} 5$ caused the $\mathrm{MC}_{1} / \mathrm{MC}_{4}$ receptor selectivity (see Table 4 ).

\section{Verification of predictions using mutagenesis}

In order to assess the predictions for the ten amino acid positions predicted with by the model based on physicochemical properties of amino-acids located inside the receptors transmembrane regions, they were subjected to single, double, triple, pentuple, and heptuple mutations in the $\mathrm{MC}_{4}$ receptor, replacing them with the correspond- ing amino acids in the $\mathrm{MC}_{1}$ receptor. Measurements taken from the mutants showed that seven positions gave the expected increase in affinity for $\alpha$-MSH (see Fig. 2, Table 5). Combining amino acid substitutions also gave higher increases in affinity than did the single point mutations (see Fig. 2, Table 5).

However, three of the ten positions (A89S, I102A and I251L) did not show the predicted increase in affinity (see Fig. 2, Table 5). The failure of the A89S and I102A mutations to increase the affinity of the $\mathrm{MC}_{4}$ receptor can be 


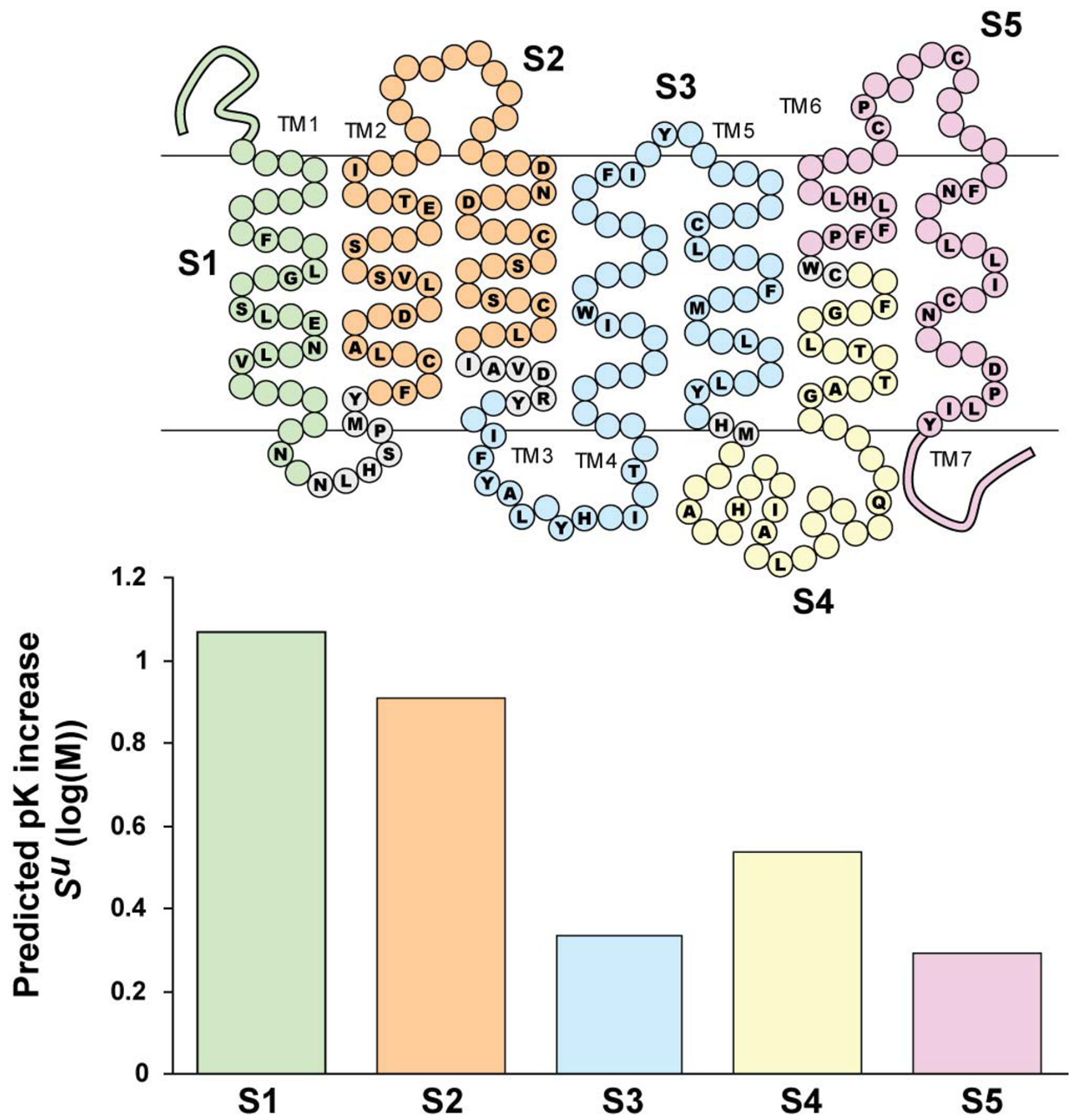

Figure I

Increase in affinity of $\alpha$-MSH predicted from the binary proteochemometric model. Shown is the increase in affinity $S^{U}(\log (M))$ for $\alpha-M S H$ afforded by swapping each of segments SI - S5 in the $\mathrm{MC}_{4}$ receptor with the corresponding segment in the $M C_{1}$ receptor as predicted from the binary proteochemometrics model.

explained by the presence of several amino acid positions in the protein library that show the same or similar variability (i.e., they co-vary). For example, positions A89 and
A135 (numbered according to the $\mathrm{MC}_{4}$ receptor) both reside in the same segment and are serines in the $\mathrm{MC}_{1}$ receptor and alanines in the $\mathrm{MC}_{3}, \mathrm{MC}_{4}$, and $\mathrm{MC}_{5}$ recep- 

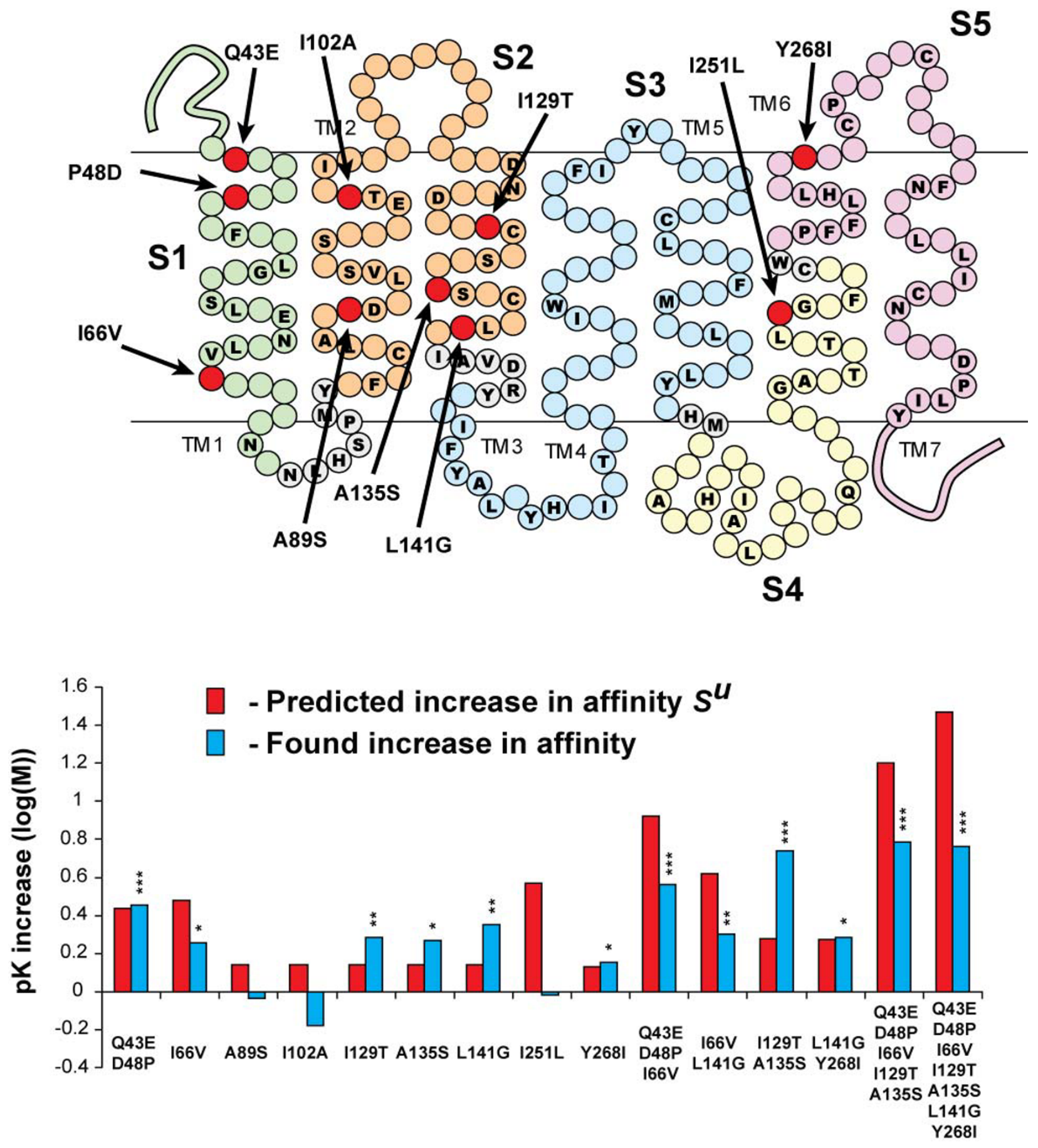

Figure 2

Predicted and experimentally determined increase in $\alpha-M S H$ affinity for site-directed mutants. Predicted and experimentally determined increase in affinity (i.e., computed $S U$ and measured pK increase, $\log (M)$ ), respectively) for $\alpha-M S H$ afforded by point mutations in the $\mathrm{MC}_{4}$ receptor. Shown by red bars is the change in affinity predicted by the model utilizing physicochemical descriptions of amino acids of the receptors' transmembrane regions and facing potential ligand binding clefts to be afforded by the indicated point mutations (i.e., the predicted increase in affinity that should be gained by exchanging the indicated amino acids in the $\mathrm{MC}_{4}$ receptor with the corresponding ones in the $M C_{1}$ receptor). Shown in blue bars is the experimentally determined change in affinity for these mutations vs. the wild-type $\mathrm{MC}_{4}$ receptor. Significance (nonparametric Wilcoxon Rank Sum statistical test [29]) denoted as follows: ${ }^{*} p<0.05$; $* * p<0.005 ; * * p<0.0005$. 
Table 5: Experimentally determined pK values of $\alpha-M S H$ for $M_{4}$ receptor mutants. Shown is the average pK \pm SD determined in radioligand binding competition using [ ${ }^{125}$ I]NDP-MSH as radioligand. (The numbers of independent replicates are in brackets). The significance, $p$, is calculated using nonparametric Wilcoxon Rank Sum test [29] (see Methods for details), when compared with the wild-type $\mathrm{MC}_{4}$ receptor.

\begin{tabular}{|c|c|c|}
\hline Name & $\mathrm{pK}_{\mathrm{i}}(\log (\mathrm{nM})) \pm \mathrm{SD}$ (Repeats) & $P$ \\
\hline$M_{4}$ & $5.73 \pm 0.32(22)$ & - \\
\hline Q43E/P48D & $6.19 \pm 0.14(11)$ & I.3E-4 \\
\hline $166 \mathrm{~V}$ & $5.98 \pm 0.26(12)$ & $9.8 \mathrm{E}-3$ \\
\hline A89S & $5.69 \pm 0.14(14)$ & $6.4 \mathrm{E}-\mathrm{I}$ \\
\hline $1102 \mathrm{~A}$ & $5.56 \pm 0.30(12)$ & I.8E-I \\
\hline $1129 \mathrm{~T}$ & $6.02 \pm 0.15(11)$ & 4.IE-3 \\
\hline Al35S & $6.00 \pm 0.15(10)$ & I.0E-2 \\
\hline LI4IG & $6.08 \pm 0.15(9)$ & $3.0 \mathrm{E}-3$ \\
\hline $\mathrm{I} 25 \mathrm{IL}$ & $5.71 \pm 0.36(10)$ & $7.0 \mathrm{E}-1$ \\
\hline Y268I & $5.88 \pm 0.20(14)$ & $3.8 \mathrm{E}-2$ \\
\hline Q43E/P48D/166V & $6.30 \pm 0.17(11)$ & $1.5 \mathrm{E}-5$ \\
\hline $166 \mathrm{~V} / \mathrm{LI} / 4 \mathrm{IG}$ & $6.03 \pm 0.20(\mathrm{II})$ & $4.6 \mathrm{E}-3$ \\
\hline II29T/AI35S & $6.47 \pm 0.5 \mathrm{I}(10)$ & $2.3 \mathrm{E}-5$ \\
\hline LI4IG/Y268I & $6.01 \pm 0.27(12)$ & $9.8 \mathrm{E}-3$ \\
\hline Q43E/P48D/I66V/II29T/AI35S & $6.52 \pm 0.17(\mathrm{II})$ & $1.4 \mathrm{E}-7$ \\
\hline Q43E/P48D/I66V/II29T/AI35S/LI4IG/Y286| & $6.49 \pm 0.31(9)$ & $1.8 \mathrm{E}-5$ \\
\hline N240G/M24IL/I245V & $6.10 \pm 0.10(5)$ & I.IE-2 \\
\hline $\mathrm{V} 253 \mathrm{I} / \mathrm{V} 255 \mathrm{~F} / \mathrm{V} 256 \mathrm{~L}$ & $6.19 \pm 0.16(5)$ & $4.3 \mathrm{E}-3$ \\
\hline IL3 & $6.72 \pm 0.14(5)$ & I.7E-5 \\
\hline S4 & $6.98 \pm 0.17(5)$ & I.7E-5 \\
\hline
\end{tabular}

tors. Such co-varying sequence positions gain equal importance in a proteochemometric model, even when some of them are not responsible for the explained activity. In the present library, mutations A89S, I102A, I129T, A135S, and L141G represent co-varying amino acid positions. The failure of the A89S and I102A mutations to cause the predicted increase in affinity may thus be explained on the basis of co-variance, where the actual effect is caused by mutations I129T, A135S, and L141G. In fact, the sum of the experimentally determined affinity increase by mutations A89S, I102A, I129T, A135S, and L141G ( $\mathrm{pKi}=0.69$ ) closely agrees with that predicted from the model $\left(S^{U}=0.56\right)$.

However, the failure of mutation I251L to increase affinity could not be explained by co-variances of amino acids within the model. Accordingly the predicted effect must originate from amino acids actually co-varying in the library but excluded from the modelling in the selections of amino acids based on 3D structure. Three such possible excluded positions partially co-varying with I251 are found in the midst of TM6, three are found towards the intracellular face of the lipid bi-layer in TM6, and several are present in the third intracellular loop. In the 3D structure, these amino acids are obviously located very far from any eventual binding pocket for $\alpha-M S H$. To verify the prediction that these positions are responsible for the 'missing' affinity they were mutated separately and in combinations (see Fig. 3, Table 5). Although all mutations afforded an increase in affinity, most of the increase
( 12 -fold) was afforded by swapping the entire third intracellular loop (see Fig. 3, Table 5). (Mutating all of these positions together afforded an $\sim 20$-fold increase in affinity).

\section{Discussion}

The experimental data demonstrate the utility of proteochemometrics for mapping ligand recognition. Using it seven amino-acid positions and the third intracellular loop were identified as accounting for most of the difference in affinity of the $\mathrm{MC}_{1}$ and $\mathrm{MC}_{4}$ receptor for $\alpha-\mathrm{MSH}$. The ability to localize a distant effect in a protein distinguishes proteochemometrics from other approaches to mapping molecular recognition. A general scheme for mapping ligand recognition using proteochemometrics is outlined in Fig. 4. The protein library might initially be collected from wild-type proteins, or created by constructing multiple chimeric proteins, as performed in this study. Applying experimental design could, in both cases, substantially reduce the number of entities that need to be constructed and tested without detrimentally compromising the information gained [2]. The application of proteochemometric modelling to the data creates a selectivity recognition map for the proteins and ligands. Analyzing the map (e.g., using Eq. 5) reveals the regions in the proteins involved in recognition of the ligands in a data-set. Regions of high interest can then be identified and analyzed further by extending the library, if necessary, in order to remove ambiguities due to co-variances (Fig. 4). In the selection of the regions for mutations the present 

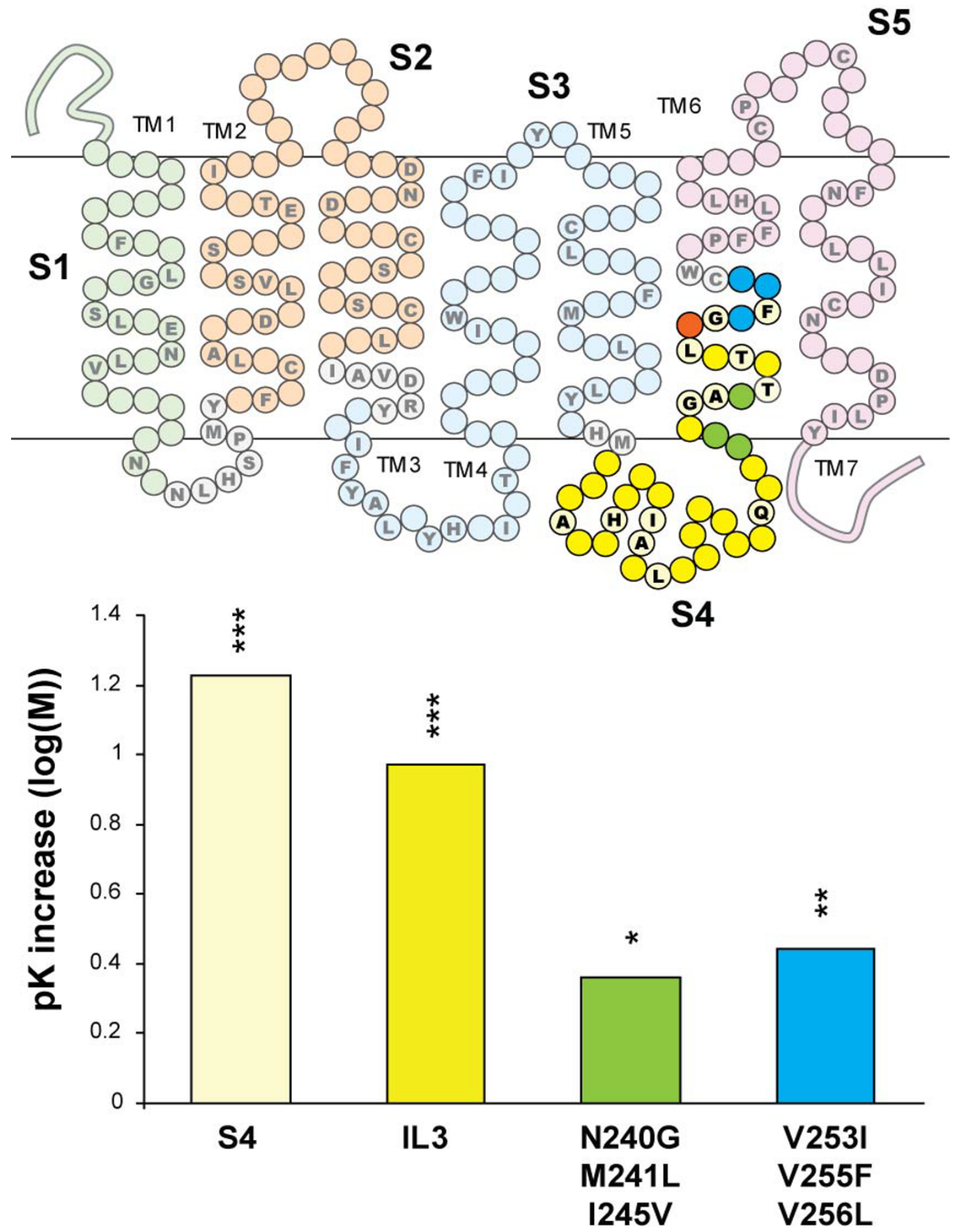

Figure 3

Experimentally determined increase in $\alpha-M S H$ affinity by mutations in segment S4. Experimentally determined increase in affinity (pK) afforded by mutations N240G/M24I L/I245V (indicated in green), and V253I/V255F/V256L (indicated in blue) (i.e., exchanging amino acid residues in the $M C_{4}$ receptor with the corresponding residues in the $M C_{1}$ receptor), and swapping intracellular loop 3 (IL3, indicated in dark yellow) in the $M_{4}$ receptor with the corresponding in the $M C_{1}$ receptor. Also shown is the increase in affinity for the whole S4 segment (S4, indicated in pale yellow). Significance (nonparametric Wilcoxon Rank Sum statistical test [29]) denoted as indicated in the legend to Fig. 2. 


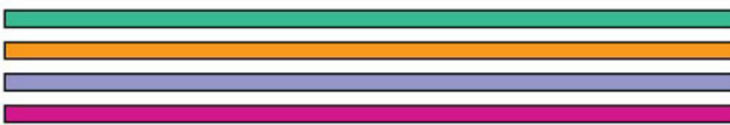

Set of macromolecules

\title{
\Statistical molecular design
}



\author{
Library of chimeric \\ macromolecules
}

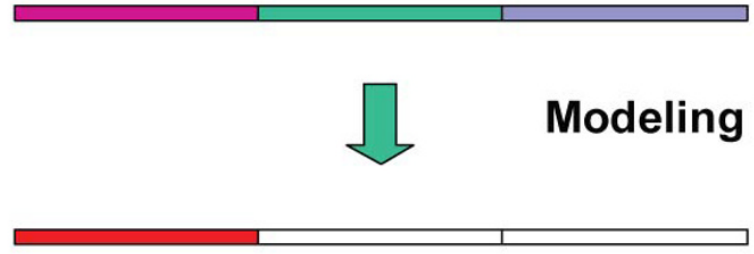

\section{Localization of contribution}

\section{Statistical molecular design}

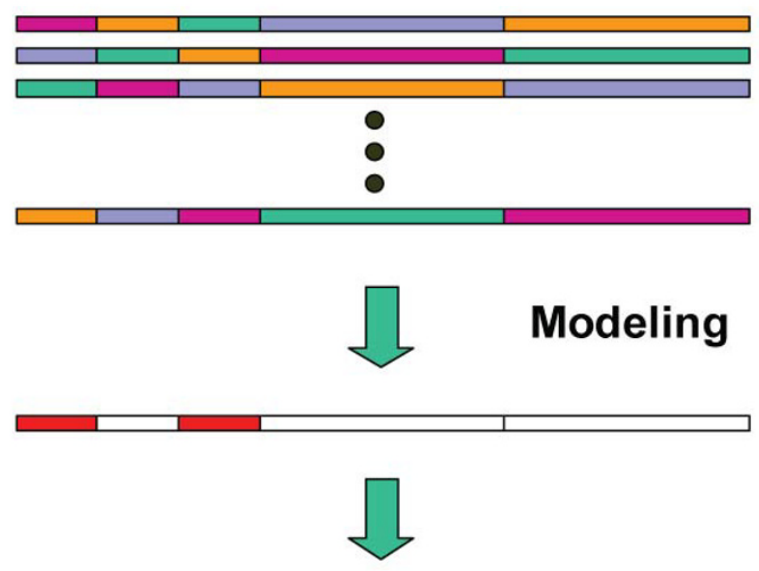

\author{
Next library of chimeric \\ macromolecules
}

\section{Localization of contribution}

\section{Next iteration}

\section{Figure 4}

Outline of the mapping of direct and indirect interactions in molecular recognition using proteochemometrics. Outline of a general procedure for mapping molecular recognition by biomacromolecules. Initially, sets of wild-type macromolecules are identified. Using statistical molecular design a library is then created from the wild-type macromolecules. The library can be selected from the wild-type molecules if the initial collection contains sufficient chemical variation. Chemical variation may also be introduced artificially by mutagensis. Shuffling sequence fragments can then be used to create a library,

where three or more segments and three or more macromolecules are used as the starting point. After evaluating the interaction of the library with a suitable library of ligands of interest, a proteochemometric model can be created. This model may be used to localize the regions in each macromolecule that contribute to the selectivity of each particular ligand evaluated. It may happen that it is not possible to unambiguously localize individual amino acids within a particular region, due to co-varying amino acid positions in the macromolecular library. In that case, an extension of the library can be made in order to resolve the ambiguity. 
study shows that also distant effects on protein function should be taken into account. Overall the approach would lead to a substantial gain in information at reduced experimental effort

Mapping molecular recognition with proteochemometrics obtains different information than 3D-structurebased methods. The latter generally reveal where one particular ligand touches one particular receptor in one of many bound states. Proteochemometrics, by contrast, reveals regions of biomacromolecules that influence the selectivity of their ligand binding, and it has the capacity to predict effects arising from distant sites in a protein. The information obtained is only partially overlapping and, therefore, the approaches complement each other. The information gained in proteochemometrics relates to protein function and has direct utility for changing the function of a protein in a desired direction by mutation, in $a$ priori protein engineering, or by altering the structure of a chemical entity and improving its interaction with binding sites, in a priori drug design [2].

\section{Conclusion}

In the present work we have presented a theoretical basis for the use of proteochemometrics to assess direct and indirect interactions in proteins, and we verified its utility to this end experimentally. We have also outlined a general strategy to afford cost effective mapping of molecular recognition using proteochemometrics and indicate important differences of proteochemometric mapping of ligand recognitions compared to traditional three-dimensional approaches. We propose that proteochemometrics can be used as a complement to classical 3D based methods to the study of ligand recognition, or even as the prime choice, in particular when three-dimensional protein structures are not available. Moreover, since proteochemometrics can be used to map both direct and indirect interactions, it may find a more general use in e.g. protein engineering and mapping protein function.

\section{Methods}

\section{Receptor clones and multichimeric receptors}

The coding sequences of the $\mathrm{MC}_{1}$ and $\mathrm{MC}_{5}$ receptors were cloned earlier $[13,14]$. The coding sequences of the $\mathrm{MC}_{3}$ and $\mathrm{MC}_{4}$ receptor were gifts of Dr. Ira Gantz $[15,16]$. Multichimeric $\mathrm{MC}_{1,3-5}$ receptors were constructed so that each receptor was divided into three regions, with each region being replaced with a corresponding region from one of the four wild-type $\mathrm{MC}_{1,3-5}$ receptors. Swapping all segments from the four receptors would have created a library with an extensive number of combinations, but this would have been impractical. We applied a statistical molecular design, which combines statistical approaches to maximize information gained from a minimal number of experiments. We used a D-optimal design, which could approximate all combinations of the melanocortin receptor regions making up 16 receptors, of which 4 were wildtype and 12 were multiple chimeric receptors. The multiple chimeric receptors were constructed in two sets, the Fand S-sets. The divisions were made at the end of the third and fifth transmembrane segments for the F-set (9 receptors of the 12 designed could be obtained), and at the beginning of the second and middle of the sixth transmembrane segments for the S-set ( 5 receptors were thus obtained, completing the library according to the design). Thus, the library came to include a total of 18 receptors: 14 that were multiple chimeric (in five segments) and four wild-type $\mathrm{MC}_{1,3-5}$ receptors. We have previously reported a full account of the construction of this receptor library [7]. Moreover, full accounts of the theory and applicability of statistical molecular design have also been reported previously [8-10].

\section{Site-directed mutagenesis}

Selected individual amino acids in the $\mathrm{MC}_{4}$ receptor were exchanged for the corresponding amino acids of the $\mathrm{MC}_{1}$ receptor, using mutation-inducing primers and PCR [17]. Eight single mutants (I66V, A89S, I102A, I129T, A135S, L141G, I251L, and Y268I), a double mutant (Q43E/ P48D), and two triple mutants (N240G/M241L/I245V, V253I/V255F/V256L), were created. Some of these mutants were then used as templates for constructing mutants with multiple mutations, yielding I66V/L141G, I129T/A135S， L141G/Y268I，Q43E/P48D/I66V，Q43E/ $\mathrm{P} 48 \mathrm{D} / \mathrm{I} 66 \mathrm{~V} / \mathrm{I} 129 \mathrm{~T} / \mathrm{A} 135 \mathrm{~S}$, and Q43E/P48D/I66V/I129T/ A135S/L141G/Y268I. We also manufactured two chimeric receptors in which subsequences of the $\mathrm{MC}_{4}$ receptor were replaced by the corresponding subsequences of the $\mathrm{MC}_{1}$ receptor. First we constructed a receptor ("S4 chimeric receptor") in which the entire S4 segment in the $\mathrm{MC} 4$ receptor was replaced with that from the $\mathrm{MC}_{1}$ receptor. Another receptor ("IL3 chimeric receptor") comprised the $\mathrm{MC}_{4}$ receptor with intracellular loop 3 replaced with the corresponding loop of the $\mathrm{MC}_{1}$ receptor.

\section{Peptides and radioligand}

Peptide ligands $\alpha$-MSH (Ac-SYSMGHFRWGKPV-NH ${ }_{2}$ ) and NDP-MSH ([Tyr $\left.\left.{ }^{2}, \mathrm{Nle}^{4}, \mathrm{D}-\mathrm{Phe}^{7}\right]-\alpha-\mathrm{MSH}\right)$ were synthesized using standard solid phase peptide synthesis and purified by HPLC; their correct molecular weights were verified by mass spectrometry. [125I]-NDP-MSH ([125I$\left.\left.\mathrm{Tyr}^{2}, \mathrm{Nle}^{4}, \mathrm{D}-\mathrm{Phe}^{7}\right]-\alpha-\mathrm{MSH}\right)$ was prepared in radiochemically pure form by custom iodination at EuroDiagnostica $\mathrm{AB}$, Sweden.

\section{Receptor expression and radioligand binding}

COS-1 cells were grown in Dulbecco's modified Eagle's medium with $10 \%$ fetal calf serum. Eighty-percent confluent cultures were transfected in 100-mm dishes with the DNA constructs $(10 \mu \mathrm{g}$ DNA per dish, mixed with lipo- 
Table 6: Description of peptides for proteochemometric modelling. The general sequence of the peptides used herein was: Ac-SerPos2-Ser-Pos4-Gly-His-Pos7-Arg-Trp-Gly-Lys-Pro-Val-NH ${ }_{2}$. Amino acids in Pos2, Pos4, Pos7, and the corresponding description, were as shown.

\begin{tabular}{|c|c|c|c|c|c|c|}
\hline \multirow[t]{2}{*}{ Peptides } & \multicolumn{3}{|c|}{ Sequence position } & \multicolumn{3}{|c|}{ Descriptors } \\
\hline & Pos2 & Pos 4 & Pos7 & $Y$ & $\boldsymbol{F}$ & $Y * F$ \\
\hline$\alpha-M S H$ & Tyr & Met & Phe & -1 & -1 & 1 \\
\hline NDP-MSH & Tyr & $\mathrm{Nle}$ & D-Phe & -1 & 1 & -1 \\
\hline 125I-NDP-MSH & $125 \mid-\mathrm{Tyr}$ & $\mathrm{Nle}$ & D-Phe & 1 & 1 & I \\
\hline
\end{tabular}

somes, as described [18]. Twelve to sixteen hours after transfection, the serum-free medium was replaced with growth medium and the cells were cultivated for approximately 48 hours, then scraped off, centrifuged, and used for radioligand binding. Dissociation constants $\left(K_{d}\right)$ for [125I]-NDP-MSH were estimated for all the receptors by radioligand binding saturation as described $[7,18]$. Inhibition constants $\left(\mathrm{K}_{\mathrm{i}}\right)$ for $\alpha$-MSH and NDP-MSH were then estimated in competition with [125I]-NDP-MSH using established procedures $[7,18]$. Obtained $\mathrm{pK}$ values (i.e., the negative logarithms of the $\mathrm{K}_{\mathrm{i}}$ and $\mathrm{K}_{\mathrm{d}}$ values) are listed in Tables 1 and 5.

\section{Numerical descriptions of receptors for proteochemometric modelling}

Two types of descriptions were used for the receptors, namely a binary description and a description based on physicochemical descriptions of amino acids. For the binary description, four binary numbers described each region, with each number corresponding to one receptor subtype. Each of these descriptors was assigned a value of +1 if the region was taken from descriptors' corresponding receptor subtype, otherwise it was assigned the number -1 [7].

The receptor descriptions based on physicochemical descriptions of amino acids at 38 selected sequence positions was used as described [7]. These positions were selected from a three-dimensional model of the transmembrane regions of the $\mathrm{MC}_{1}$ receptor.

Using the crystal structure coordinates of rhodopsin as a template [12], the model was derived by replacing the side chains with the corresponding side chains of the $\mathrm{MC}_{1}$ receptor, using the alignments of the GPCRDB database [19] and the SCWRL program [20]. Only amino acids pointing in the direction opposite the lipid bilayer were considered. This led to a considerable reduction in the number of co-varying sequence positions considered in the proteochemometric modelling, albeit with the obvious risk of excluding important positions. The selected positions are listed in Table 4.

Each position was coded by using five principal components derived from 26 physicochemical properties of amino acids, so called z-scales [21]. These z-scales represent hydrophobicity, steric properties, polarizability (z1z3), polarity, and electronic effects $(z 4, z 5)$. The data for the $38 \times 5=190$ descriptors obtained were compressed by applying principal component analysis (PCA) [22] to each of the five segments of the receptor library, which yielded in total 15 descriptors, with three descriptors for each segment. Prior to PCA, the z-scale descriptors had been scaled to unit variance [23]. Principal component analysis was performed using the Simca-P program [23].

\section{Numerical description of peptides for proteochemometric modelling}

The three peptide ligands used showed limited structural variation and were assigned two binary descriptors termed $\boldsymbol{Y}$ and $\boldsymbol{F}$, using the Free-Wilson approach [24]. $\boldsymbol{Y}$ was set to +1 if the $\mathrm{Tyr}^{2}$ residue of the peptides was iodinated; otherwise it was set to -1 . Thus, ligand descriptor $Y$ distinguished between [125I]-NDP-MSH and the other two peptides. The descriptor $\boldsymbol{F}$ was set to +1 if $\mathrm{Phe}^{7}$ was in the D-conformation and there was an Nle at position 4; otherwise it was set to -1. Thus, ligand descriptor F distinguished between $\alpha-\mathrm{MSH}$ and the other two ligands. We also included the cross-term formed between the peptide descriptors $Y$ and $F$ (termed $Y^{*} F$ ). This cross-term distinguishes NDP-MSH from $\alpha$-MSH and [125I]-NDP-MSH. The peptide ligand description is summarized in Table 6.

\section{Numerical description of binding experiments and proteochemometric modelling}

In each binding experiment, the receptor-peptide combination was described using the above receptor and peptide descriptors, and by computing receptor-ligand crossterms using Eq. 2, each cross-term being calculated as the product of one peptide and one receptor descriptor. Prior to calculating cross-terms, all descriptors were mean-centred and scaled to unit variance [23]. In order to account for differences in the number and mutual correlation of each descriptor type, the peptide descriptors, receptor descriptors, and cross-terms, block scaling was applied. All descriptors and cross-terms were mean centred and scaled to unit variance prior to block scaling [23]. Descriptors were finally correlated to the $\mathrm{pK}$ values using partial least squares projection to latent structures (PLS) regression [22]. PLS modelling was done using Simca-P [23]. 


\section{Validation of modelling}

The goodness-of-fit was estimated by the correlation coefficient $\mathrm{R}^{2}$ and root mean square error (RMSE) [23]. Models were further validated using cross-validation (CV) $[25,26]$, validation by response permutations [27], and validation by external prediction.

In cross-validation, one divides the data into several fractions. Seven were used in this study. Each fraction is repeatedly excluded once and then predicted from the model developed on the remaining data. The goodness of prediction of the CV is assessed by the $\mathrm{Q}^{2}$ measure [23].

In response permutation validation, many models are created using randomly permuted response data. Twenty permutations were used here. For each permuted model, the $\mathrm{R}^{2}, \mathrm{Q}^{2}$, and correlation coefficients between the original and permuted response values are estimated. The correlation coefficients are plotted against the $\mathrm{R}^{2}$ and $\mathrm{Q}^{2}$ values. The two corresponding linear correlation lines are estimated, one for $\mathrm{R}^{2}$ and one for $\mathrm{Q}^{2}$, and the intercepts $\mathrm{iR}^{2}$ and $\mathrm{iQ}^{2}$ of the two regression lines with the zero correlation coefficient line are calculated $[5,23]$. These intercept values indicate the $\mathrm{R}^{2}$ and $\mathrm{Q}^{2}$ of random response data. For example, a negative $\mathrm{Q}^{2}$ intercept shows that it is not possible to obtain predictive models with random data, and indicates that a high $\mathrm{Q}^{2}$ value of the original model is not obtained by pure chance.

External prediction assesses a model's stability when a substantial fraction of the data is excluded (e.g., more than one-third). External prediction may aim to predict the properties of new entities, in other words, entities that are entirely excluded from the data set. In the present case we predicted $\mathrm{pKs}$ for the S-set receptors using only data for F-set receptors. The goodness of external prediction was assessed by the external $\mathrm{Q}^{2}\left(\mathrm{eQ}^{2}\right)$ value [5]. Further details on these model validation approaches and how to interpret their results have been previously reported [28].

\section{Computation of the selectivity contribution of amino acids} The contributions of individual amino acids to the selectivity of peptide binding between pairs of receptors were computed using Eq. 5. In order to apply Eq. 5, the regression coefficients for the individual $\mathrm{z}$-scales of the receptor's amino acids were computed from the corresponding PLS and PCA models. Nine amino acids (Q43, P48, I66, A89, I102, I129, L141, I251, Y268, according to the numbering in the $\mathrm{MC}_{4}$ receptor) contributed most to the selectivity of $\alpha-\mathrm{MSH}$ (see Table 4) and were selected for sitedirected mutagenesis. Moreover, upon analyzing the $3 \mathrm{D}$ model of the $\mathrm{MC}_{1}$ receptor it was deemed that $\mathrm{S} 83$ (corresponding to $\mathrm{A} 89$ in the $\mathrm{MC}_{4}$ receptor) had a strong $\mathrm{H}$ bond interaction with $\mathrm{S} 130$ (A135 in the $\mathrm{MC}_{4}$ receptor). Since the amino acid positions A89/A135 (MC 4 receptor numbering) showed identical co-variance in the receptor library, A135 was also selected for site-directed mutagenesis.

\section{Statistical tests}

The distribution of measured affinity for $\mathrm{MC}_{4}$ receptor and mutant receptors presented here as well as its logarithm values $(\mathrm{pK})$ did not correspond to normal distribution. Therefore we decided to use nonparametric Wilcoxon Rank Sum statistical test [29] to verify the hypothesis that affinity for corresponding mutant receptor differs from wild-type $\mathrm{MC}_{4}$ receptor. The test was performed using R program [30].

\section{Authors' contributions}

PP did most of modeling, data analysis and interpretation and manuscript preparation work. SU was responsible for all molecular biology work. RP assisted SU as well as performed pharmacological measurements. ML gave significant intellectual contribution for modeling, data analysis and interpretation. JESW was the major initiator of the project and supervisor of it and he contributed significantly to drafting the manuscript.

\section{Acknowledgements}

Supported by the Swedish Research Council (04X-05957 and 62I-200247II). We thank Santa Veiksina for technical assistance.

\section{References}

I. Prusis P, Muceniece R, Andersson P, Post C, Lundstedt T, Wikberg JE: PLS modeling of chimeric MS04/MSH-peptide and MCI/ MC3-receptor interactions reveals a novel method for the analysis of ligand-receptor interactions. Biochim Biophys Acta 200I, I 544(I-2):350-357.

2. Wikberg JES, Lapinsh M, Prusis P: Proteochemometrics: $\mathbf{A}$ tool for modelling the molecular interaction space. In Chemogenomics in Drug Discovery - A Medicinal Chemistry Perspective Edited by: Kubinyi H, Müller G, Mannhold R, Folkers G. Weinheim: Wiley-VCH; 2004:289-309.

3. Lapinsh M, Prusis P, Gutcaits A, Lundstedt T, Wikberg JE: Development of proteo-chemometrics: a novel technology for the analysis of drug-receptor interactions. Biochim Biophys Acta 200I, I 525(I-2): I $80-190$.

4. Lapinsh M, Prusis P, Lundstedt T, Wikberg JE: Proteochemometrics modeling of the interaction of amine G-protein coupled receptors with a diverse set of ligands. Mol Pharmacol 2002, 6I(6): I 465-I 475.

5. Prusis $P$, Lundstedt T, Wikberg JE: Proteo-chemometrics analysis of MSH peptide binding to melanocortin receptors. Protein Eng 2002, I 5(4):305-3II.

6. Lapinsh M, Prusis P, Mutule I, Mutulis F, Wikberg JE: QSAR and proteo-chemometric analysis of the interaction of a series of organic compounds with melanocortin receptor subtypes. J Med Chem 2003, 46( I 3):2572-2579.

7. Lapinsh M, Veiksina S, Uhlén S, Petrovska R, Mutule I, Mutulis F, Yahorava $S$, Prusis $P$, Wikberg JE: Proteochemometric mapping of the interaction of organic compounds with melanocortin receptor subtypes. Mol Pharmacol 2005, 67(I):50-59.

8. Linusson A, Wold $S$, Nordén B: Statistical molecular design of peptoid libraries. Mol Divers 1998, 4(2): 103-1 I4.

9. Lundstedt T, Seifert E, Abramo L, Thelin B, Nystrom A, Pettersen J, Bergman R: Experimental design and optimization. Chemometrics and Intelligent Laboratory Systems 1998, 42(I-2):3-40.

10. Linusson A, Gottfries J, Lindgren F, Wold S: Statistical Molecular Design of Building Blocks for Combinatorial Chemistry. J Med Chem 2000, 43(7): I 320-। 328. 
11. Prusis P, Schiöth HB, Muceniece R, Herzyk P, Afshar M, Hubbard RE, Wikberg JE: Modeling of the three-dimensional structure of the human melanocortin I receptor, using an automated method and docking of a rigid cyclic melanocyte-stimulating hormone core peptide. J Mol Graph Model 1997, I5(5):307-17. 334

12. Palczewski K, Kumasaka T, Hori T, Behnke CA, Motoshima H, Fox BA, Le Trong I, Teller DC, Okada T, Stenkamp RE, Yamamoto M, Miyano M: Crystal structure of rhodopsin: A G protein-coupled receptor. Science 2000, 289(5480):739-745.

13. Chhajlani V, Wikberg JE: Molecular cloning and expression of the human melanocyte stimulating hormone receptor cDNA. FEBS Lett 1992, 309(3):417-420.

14. Chhajlani V, Muceniece R, Wikberg JE: Molecular cloning of a novel human melanocortin receptor. Biochem Biophys Res Commun 1993, 195(2):866-873.

15. Gantz I, Konda Y, Tashiro T, Shimoto Y, Miwa H, Munzert G, Watson S], DelValle J, Yamada T: Molecular cloning of a novel melanocortin receptor. J Biol Chem 1993, 268(I I):8246-8250.

16. Gantz I, Miwa H, Konda Y, Shimoto Y, Tashiro T, Watson SJ, DelValle J, Yamada T: Molecular cloning, expression, and gene localization of a fourth melanocortin receptor. J Biol Chem 1993, 268(20): $15|74-15| 79$.

17. Ho SN, Hunt HD, Horton RM, Pullen JK, Pease LR: Site-directed mutagenesis by overlap extension using the polymerase chain reaction. Gene 1989, 77(1):51-59.

18. Schioth HB, Muceniece R, Wikberg JE: Characterisation of the melanocortin 4 receptor by radioligand binding. Pharmacol Toxicol 1996, 79(3): 16I-165.

19. Horn F, Bettler E, Oliveira L, Campagne F, Cohen FE, Vriend G: GPCRDB information system for $\mathbf{G}$ protein-coupled receptors. Nucleic Acids Res 2003, 3 I (I):294-297.

20. Bower MJ, Cohen FE, Dunbrack RL: Prediction of protein sidechain rotamers from a backbone-dependent rotamer library: a new homology modeling tool. J Mol Biol 1997, 267(5): $1268-1282$.

21. Sandberg M, Eriksson L, Jonsson J, Sjöström M, Wold S: New chemical descriptors relevant for the design of biologically active peptides. A multivariate characterization of 87 amino acids. J Med Chem 1998, 4I(14):248I-249I.

22. Geladi P, Kowalski BR: Partial least-squares regression: A tutorial. Anal Chim Acta 1986, 185: I-17.

23. SIMCA-P 9 User Guide and Tutorial Umeå: Umetrics AB; 2001.

24. Free SM, Wilson JW: A mathematical contribution to structure-activity studies. I Med Chem 1964, I:395-399.

25. Wold S: Cross-validatory estimation of the number of components in factor and principal component models. Technometrics 1978, 20:397-405.

26. Wakeling IN, Morris JJ: A test of significance for partial least squares regression. J Chemometr 1993, 7:291-304.

27. Efron B: Better bootstrap confidence intervals. J Am Stat Assoc 1987, 78: $17 \mid-200$.

28. Eriksson L, Johansson E, Wold S: Quantitative structure-activity relationship validation. In Quantitative structure-activity relationships in environmental sciences-VII Edited by: Schuurmann G, Chen F. Pensacola: SETAC; 1997:38I-397.

29. Wilcoxon F: Individual Comparisons by Ranking Methods. Biometrics 1945, I(6):80-83.

30. R Development Core Team: A language and environment for statistical computing Vienna, Austria: R Foundation for Statistical Computing; 2004.

3I. Schiöth HB, Petersson S, Muceniece R, Szardenings M, Wikberg JE: Deletions of the $\mathbf{N}$-terminal regions of the human melanocortin receptors. FEBS Lett 1997, 410(2-3):223-228.

\section{Publish with BioMed Central and every} scientist can read your work free of charge

"BioMed Central will be the most significant development for disseminating the results of biomedical research in our lifetime. "

Sir Paul Nurse, Cancer Research UK

Your research papers will be:

- available free of charge to the entire biomedical community

- peer reviewed and published immediately upon acceptance

- cited in PubMed and archived on PubMed Central

- yours - you keep the copyright
Biomedcentral 